(REVIEW ARTiCLE)

\title{
How do medical doctors respond to the inappropriate patient request?
}

\author{
Basem Abbas Al Ubaidi * \\ Consultant Family MD, Ministry of Health, Assistant professor at Arabian Gulf University (AGU), Kingdom of Bahrain.
}

Magna Scientia Advanced Biology and Pharmacy, 2021, 02(02), 006-009

Publication history: Received on 25 March 2021; revised on 05 May 2021; accepted on 08 May 2021

Article DOI: https://doi.org/10.30574/msabp.2021.2.2.0019

\begin{abstract}
Medical doctors need the skill to acquire how they are responding to inappropriate patient's requests. The FAVER approach starts with recognizing inner uncomfortable feelings, which signals that the patient's request is inappropriate. Assuming that the patient doesn't know that their demands are "immoral." The medical doctors need to say "NO" in an explicit state and give excuses such as inadequate medical care, illegal, dishonest, or against policy and avoid lengthy explanations.
\end{abstract}

Keywords: Inappropriate request; Patient's demand.

\section{Introduction}

Occasionally, various patients are asking their medical doctors (MDs) for inappropriate requests. The definition of inappropriate requests is inquiring somebody about an improper act. It is a challenging dilemma of daily practice for the health care worker. Sometimes the patients are requesting politely but occasionally in a threatening manner [1].

Inappropriate patient demands frequently happen in many ways, such as requesting an addictive drug or questioning sick leave or asking for false medical reports, or demanding unnecessary referrals and investigations [1].

The responded MDs' feelings are either having an uncomfortable state of mind or not being concerned about the harmful consequences. However, MDs are needed to know how and when to say "NO" in a compassionate, kinder way for inappropriate patient's demand [1].

The MDs need to say "NO" when they feel it is an incorrect or unsuitable request or feels it is out of their MD's duty. Sometimes the MDs say "NO" if they are deprived of plenty of time for the patient's commitment. Thus, the wise MD doesn't accept any assignments, and they can apologize and say sorry, I don't have time to resolve your problem [2].

MDs are hard to say "NO" since they are worried about the patient reaction or patient dissatisfaction. Always, MDs think about the unpleasant outcome if they say "NO" to some patients. Also, MDs fear the gray decision if they create a mistake. Nevertheless, MDs should work in their best patient's interests and not harm them [2].

The MDs should respect their jobs professionally and their reputation in the health care system; it isn't the MDs' business to satisfy every patient request. Occasionally, patients have unpleasant reactions or misbehavior responses after saying "NO" to them. Consequently, before the patient's upset, MDs need to clarify the situation, supported by the ministry of health rules and regulations. The MDs message should transfer to each patient, that the MDS is more than happy to help them properly [2].

\footnotetext{
${ }^{*}$ Corresponding author: Basem Abbas Al Ubaidi

Consultant Family MD, Ministry of Health, Kingdom of Bahrain. Head of the research team in primary care Assistant professor at Arabian Gulf University (AGU).
} 
The MD has the right to set their professional boundaries and say "NO" so that not being in hostile or unhelpful authority. The MDs should always show mutual respect in their behavior [2].

Saying "NO" isn't cruel, rude, mean, or uncaring to their patients. The MDs give their brief excuse to their patients in a practical technique. However, the MD doesn't need to tell an untruth or inflate the issue. Nevertheless, they should speak honesty to enhance MDs' reputation [2].

Moreover, the MDs don't need to say "NO" to every request. Instead, they can counterbalance when MDs have time or reason that your request is under MD's control. However, MDs shouldn't offer false appointments, and they aren't present in the duty. Also, MDs shouldn't give their patients false hope while evidence is contradictory [2].

The MDs shouldn't take more responsibility on their shoulders or aren't the right MD's specialty for patients' complaints. They aren't skilled adequately to deal with the patient request with the proper qualification to meet their demands [2].

Occasionally, if some patients are misused the weak health system for theirs's interest, besides aren't respect their MD's kindness. It is time to say. "NO," I can't do it anymore, or I don't want to do it again. The MDs shouldn't be worried about the patient's anger and don't need to have a comprehensive explanation [2].

If the MDs are obeying every patient's request, then they will regret it sooner or later. The MDs should realize it is inadequate medical care or illegal or dishonest response and against organization policy [3].

The MDs should allow themselves to think and decide sincerely without a guilty feeling or fear of hurting others $[2,3]$.

The MDs can provide an alternative solution by referring the patient to the proper channel if they don't have appropriate answers. This technique gives the MDs a more professional approach, especially if it is out of MD's experience [2,3].

The article aims to provide a structured way to teach MDs how to respond to inappropriate patient requests and improve MDs' responses to say "NO." Ultimately, it will enhance the patient's care, increase the MD's work satisfaction, and preserving the patient-doctor relationship $[2,3]$.

\section{Discussion}

When to say "NO" are learned skills and need to practice it safely, without threatening the patient-doctor relationship. The MDs should consider their physical, emotional, mental limits and MD's preferences for their honest beliefs. MDs should put emotional boundaries between their feelings versus others [4, 5].

\section{The use of the FAVER technique}

\subsection{First Step}

The MDs should reflect on any uncomfortable Feelings from the patient's request, such as anger, sadness, and frustration. The MDs need to reveal and respect their past resentment or discomfort feelings $[1,6]$.

\subsection{Second Step}

The MDs should Analyze the cause of their uncomfortable feelings because of inadequate medical care, illegal action, dishonesty, or against organization policy, leading to harmful consequences and inadequate medical care $[1,6]$.

\subsection{Third Step}

The MDs should View the patient's request by assuming that the patient doesn't know that the demand is inappropriate. The MDs should prepare the reaction antidote by being neutral to prevent further work conflict. MDs should identify their risk factors for patient-physician relationship damage (e.g., previous experiences, time pressures, fatigue, burnout, and personality disorder) $[1,6]$

Moreover, it is essential to Expect a manipulative way of the patient with substance dependence to get what they want. $[1,7,8]$ The MDs should know their limits and boundaries, while exceeding the MD's limit will expose the MDs to more doubt, guilt, and fear of uncertainty $[1,6]$. 


\subsection{Fourth Step}

The MDs should concisely Explain when the request is unsuitable (e.g., brief, transparent, and honest justification with respect). The MDs should Reply in a short, concise sentence; it is inadequate medical care, illegal, dishonest, against health care policy, or interfere with my faith. The MDs should avoid lengthy explanations, leading to exhausting and time-consuming arguments $[1,6]$.

The MDs will not agree that they provide inadequate care or do dishonest work (e.g., prescribing improper Opioid medication, fake issue job, or school certificate) $[1,6]$.

\subsection{Fifth Step}

The MD should Reestablish a patient's rapport with the use of empathy skills. The MDs should understand the patient's negative feelings (e.g., frustration, fear, and powerlessness) and make compassionate statements ("I know this isn't what you want" or "I can see you are frustrated" "I wish I can help"). Consequently, it is essential to acknowledge and agree with the patient's negative emotions rather than minimize or fix them $[1,6]$ (Table 1).

Table 1 the use of FAVER if the patient request is inappropriate

\begin{tabular}{|l|l|}
\hline \multicolumn{2}{|c|}{ Patient Request Triggers Discomfort } \\
\hline \multicolumn{1}{|c|}{ Name your feelings } & \multicolumn{1}{c|}{ Anger, sadness, and annoyance } \\
\hline $\begin{array}{l}\text { Analyze your thoughts that } \\
\text { fuel these feelings }\end{array}$ & $\begin{array}{l}\text { Poor medical care } \\
\text { Illegal, not honest, and against the policy }\end{array}$ \\
\hline $\begin{array}{l}\text { View the patients in the } \\
\text { Best Possible explanation }\end{array}$ & $\begin{array}{l}\text { The patient doesn't know the organization } \\
\text { rules and orders }\end{array}$ \\
\hline $\begin{array}{l}\text { Explicitly state the } \\
\text { requested action }\end{array}$ & $\begin{array}{l}\text { It would be: } \\
\text { poor medical care } \\
\text { Illegal, not honest, against the policy }\end{array}$ \\
\hline Reestablish rapport & Acknowledge the patient's disappointment \\
\hline
\end{tabular}

The practice of the FAVER technique isn't a natural or secure job, but it needs more MDs training to practice it, and most patients will accept it $[1,6]$.

Occasionally, some patients may threaten the MD by making incident complaints or even threatened to harm their MDs. The MD should assess the immediacy of threat or ask the patient politely to dismiss from the clinic and say to the patient..." I won't deliver poor care for my patients, or I will not do what I believe is bad for you" [6].

If the healthcare practice doesn't $t$ have a policy for responding to threatening behavior, the MDs should practice appropriate precautions to ensure their safety $[1,6]$.

Taking time to reflect on the event, make an incident report, and seek advice from a trusted colleague. Recognize their MDs roles and limitations while they aren't taking responsibility for their patients' emotional or behavioral reactions $[1,6]$.

Before MDs make a decision, they should think about the pros and cons of taking judgment and doing quick risk calculations and the cost of saying "NO." The MDs should decide whether having enough skills, talents, and times needed before saying "NO" [1, 6]. 


\section{Conclusion}

Inappropriate patient's request in the Kingdom of Bahrain is a substantial problem. Medical doctors need to have acquired learned skills to how they are responding to inappropriate patient's requests. It needs to use the FAVER technique to reduce improper prescriptions.

\section{References}

[1] Vaccaro, P. J. (1998). Five ways to say'no'effectively. Family Practice Management, 5(7), 71.

[2] Kravitz, R. L., Bell, R. A., Azari, R., Krupat, E., Kelly-Reif, S., \& Thom, D. (2002). Request fulfillment in office practice: antecedents and relationship to outcomes. Medical care, 38-51.

[3] Kane, M., \& Chambliss, M. L. (2018). Getting to no: how to respond to inappropriate patient requests. Family practice management, 25(1), 25-30.

[4] Paterniti, D. A., Fancher, T. L., Cipri, C. S., Timmermans, S., Heritage, J., \& Kravitz, R. L. (2010). Getting to "no": strategies primary care physicians use to deny patient requests. Archives of Internal Medicine, 170(4), 381-388.

[5] Elliott, C., \& Parry, S. (2003). Inappropriate requests from patients: main topic. CME: Your SA Journal of CPD, 21(1), 26-30.

[6] Ross, J. S. (2018). Physician Denial of Inappropriate Patient Requests-What If I Say No??.JAMA internal medicine, 178(1), 92-92. 